\title{
Hierarchical N-Doped Porous Carbons for Zn-Air Batteries and Supercapacitors
}

Cite as

Nano-Micro Lett.

(2020) 12:20

Received: 21 October 2019

Accepted: 29 November 2019

Published online: 10 January 2020

(C) The Author(s) 2020

\author{
Beibei Guo ${ }^{1,3}$, Ruguang Ma ${ }^{1}$, Zichuang $\mathrm{Li}^{1}$, Shaokui Guo ${ }^{1}$, Jun Luo ${ }^{3}$, Minghui Yang ${ }^{2,4}$, \\ Qian Liu ${ }^{1,2}$, Tiju Thomas ${ }^{5}$, Jiacheng Wang ${ }^{1,2} \bowtie$ \\ $\bowtie$ Jiacheng Wang, jiacheng.wang@mail.sic.ac.cn \\ 1 State Key Laboratory of High Performance Ceramics and Superfine Microstructure, Shanghai Institute \\ of Ceramics, Chinese Academy of Sciences, Shanghai 200050, People's Republic of China \\ 2 Center of Materials Science and Optoelectronics Engineering, University of Chinese Academy of Sciences, \\ Beijing 100049, People's Republic of China \\ 3 School of Materials Science and Engineering, Shanghai University, Shanghai 200444, \\ People's Republic of China \\ 4 Solid State Functional Materials Research Laboratory, Ningbo Institute of Materials Technology \\ and Engineering, Chinese Academy of Sciences, Ningbo 315201, People's Republic of China \\ 5 Department of Metallurgical and Materials Engineering, Indian Institute of Technology Madras, Adyar, \\ Chennai, Tamil Nadu 600036, India
}

\section{HIGHLIGHTS}

- Hierarchical N-doped porous carbons (NPCs) with large surface area and controllable N-doping are synthesized by ball milling, followed by pyrolysis.

- As a Zn-air battery cathode, NPCs have comparable discharge performance to precious metal catalysts and more stability.

- NPCs also exhibit an excellent specific capacity and cycling stability when used as supercapacitor electrodes.

\begin{abstract}
Nitrogen-doped carbon materials with a large specific surface area, high conductivity, and adjustable microstructures have many prospects for energy-related applications. This is especially true for $\mathrm{N}$-doped nanocarbons used in the electrocatalytic oxygen reduction reaction (ORR) and supercapacitors. Here, we report a low-cost, environmentally friendly, large-scale mechanochemical method of preparing N-doped porous carbons (NPCs) with hierarchical micro-mesopores and a large surface area via ball-milling polymerization followed by pyrolysis. The optimized NPC prepared at $1000{ }^{\circ} \mathrm{C}(\mathrm{NPC}-1000)$ offers excellent ORR activity with an onset potential $\left(E_{\text {onset }}\right)$ and half-wave potential $\left(E_{1 / 2}\right)$ of 0.9 and $0.82 \mathrm{~V}$, respectively (vs. a reversible hydrogen electrode), which are only approximately $30 \mathrm{mV}$ lower than that of $\mathrm{Pt} / \mathrm{C}$. The rechargeable $\mathrm{Zn}$-air

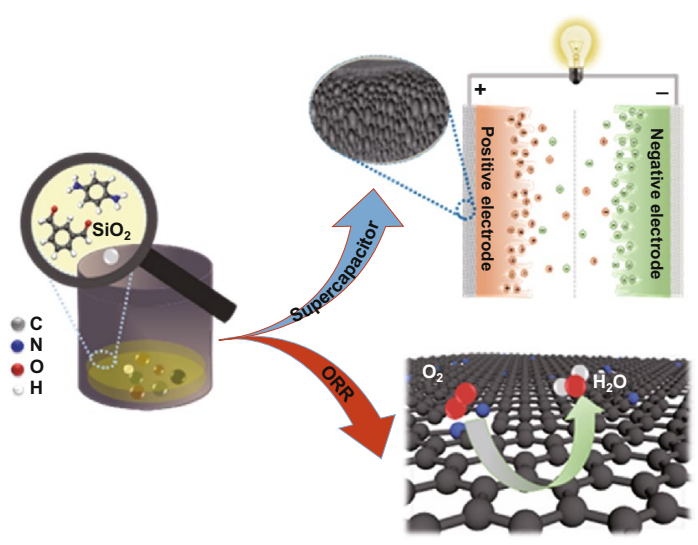
battery assembled using NPC-1000 and the NiFe-layered double hydroxide as bifunctional ORR and oxygen evolution reaction electrodes offered superior cycling stability and comparable discharge performance to $\mathrm{RuO}_{2}$ and $\mathrm{Pt} / \mathrm{C}$. Moreover, the supercapacitor electrode equipped with NPC prepared at $800{ }^{\circ} \mathrm{C}$ exhibited a high specific capacity $\left(431 \mathrm{~F} \mathrm{~g}^{-1}\right.$ at $10 \mathrm{mV} \mathrm{s}^{-1}$ ), outstanding rate, performance, and excellent cycling stability in an aqueous 6-M KOH solution. This work demonstrates the potential of the mechanochemical preparation method of porous carbons, which are important for energy conversion and storage.
\end{abstract}

KEYWORDS Porous carbon; Ball milling; Nitrogen doping; Oxygen reduction reaction; Zn-air battery; Supercapacitor 


\section{Introduction}

Traditional fossil resources are progressively being replaced by sustainable and clean energy sources. However, the movement toward a greener economy requires energy storage. Electrochemical energy devices, such as fuel cells, metal-air batteries, and supercapacitors, are expected to play a crucial role in the transition to a sustainable future [1]. The oxygen reduction reaction (ORR) is an important cathodic reaction in fuel cells and metal-air batteries. The development of highly efficient and stable ORR catalysts could resolve the bottleneck of fuel cells and metal-air batteries [2, 3]. Noble metal Pt and Pt-based alloys are the most efficient ORR electrode materials. However, although Pt-based catalysts have high ORR activity, there are several associated hindrances, such as $\mathrm{CO}$ poisoning, metal dissolution, poor stability, scanty supply of noble metals, and high costs [4]. To resolve these issues, extensive efforts have been devoted to designing high-activity and more stable non-precious metal-based ORR catalysts [5, 6]. In 2009, Gong prepared a metal-free catalyst (nitrogen-doped VA-CNT) as an ORR electrocatalyst, and its performance exceeded that of commercial Pt/C [7]. Subsequently, carbon-based electrocatalysts with other heteroatoms (such as B, P, and S) have also been developed, which exhibited excellent ORR catalytic activity [8-10]. An excellent ORR electrocatalyst typically exhibits the following characteristics: (1) a large number of active sites, (2) high specific surface area, which increases the three-phase boundary and active surface area [11], (3) outstanding conductivity, which accelerates electron transfer during electrocatalysis, and (4) excellent stability, which must be considered in practical applications. The high specific surface area and high conductivity considered desirable here are also required in supercapacitors [12].

Among the many metal-free catalysts, $\mathrm{N}$-doped porous carbon (NPC) could be used in precious metal catalysts due to its high catalytic activity and specific surface area, good electrical and thermal conductivity, and easily adjustable microstructure [2, 9, 13, 14]. Furthermore, NPCs could improve the capacitance of the catalyst via surface Faradaic reactions [15]. Micropores play an important role in the adsorption of ions [16, 17], while mesopores accelerate the transport of ions to the bulk of the material $[18,19]$. Hierarchical micro-mesoporous structures can provide numerous accessible active sites and accelerate the mass transport of ORR-related species $\left(\mathrm{O}_{2}\right.$, protons, and $\left.\mathrm{H}_{2} \mathrm{O}\right)$ [20-22]. $\mathrm{Li}$ et al. demonstrated that $\mathrm{N}$-doped hierarchical porous carbon (N-HPC) has a larger specific surface area, faster charge transferability, and better surface wettability than undoped HPC [23, 24].

The pyrolysis of $\mathrm{N}$-containing organic polymers is a very simple and efficient method of preparing NPCs and allows a certain degree of morphological control [25-27]. The porosity and catalytic activity of the NPC can be optimized by adjusting the carbonization temperature [27]. However, the synthesis of $\mathrm{N}$-containing polymers often requires the use of catalysts or large amounts of organic solvents to promote the reaction. Thus, the synthesis process is relatively complicated [25-27]. In addition, the mass use of organic solvents may also cause harm to both humans and the environment; therefore, the process requires further improvement. Compared to the various strategies for preparing NPCs, ball milling induces chemical polymerization reactions by mechanical force, which is a scalable, solvent-free, low-cost, environmentally and economically sustainable approach [28-30]. Additionally, ball mills are common in modern industrial production; therefore, preparing NPCs by a mechanochemical method is more likely to result in a technology that can be translated.

Herein, we explore a mechanochemical strategy of synthesizing $\mathrm{N}$-containing polymer precursors using planetary ball mills without solvents and catalysts with isophthalaldehyde and p-phenylenediamine as the carbon sources. During ball milling, the amine and aldehyde groups condense, leading to the formation of polyamine-based polymers [31]. The pyrolysis of such polymer precursors would produce NPCs with large numbers of micropores [27, 31]. To optimize the pore structure, we introduced nanosized $\mathrm{SiO}_{2}$ spheres as a template to produce mesoporous structures during ball milling. The hierarchical NPC is obtained by the pyrolysis of the polymer precursor containing $\mathrm{SiO}_{2}$, followed by the removal of the $\mathrm{SiO}_{2}$ template. The resultant NPC has a large specific surface area (641-1013 $\left.\mathrm{m}^{2} \mathrm{~g}^{-1}\right)$, the abundant micropores and mesopores which are beneficial for the adsorption and transport of ions and reactants. NPC-1000, which was prepared at $1000{ }^{\circ} \mathrm{C}$, exhibits excellent ORR activity in $\mathrm{KOH}$ solutions. The onset potential ( $E_{\text {onset }}$, defined as the potential when the current density reaches $0.1 \mathrm{~mA} \mathrm{~cm}^{-2}$ ) and halfwave potential $\left(E_{1 / 2}\right)$ of NPC-1000 are only $30 \mathrm{mV}$ lower than those of commercial Pt/C. However, the stability and methanol tolerance of NPC-1000 are much better than that of Pt/C. Zn-air batteries (ZABs) with an NPC-1000 
cathode achieve a high open-circuit voltage of $1.43 \mathrm{~V}$, and comparable discharge performance and energy density to those of $\mathrm{Pt} / \mathrm{C}$. Its cycling stability is also better than that of $\mathrm{Pt} / \mathrm{C}$. Furthermore, owing to the higher nitrogen content and hierarchical pore structure, NPC-800 exhibits outstanding capacitive behavior as a supercapacitor electrode $(256 \mathrm{~F}$ $\mathrm{g}^{-1}$ at $0.5 \mathrm{~A} \mathrm{~g}^{-1}$ and $431 \mathrm{~F} \mathrm{~g}^{-1}$ at $10 \mathrm{mV} \mathrm{s}^{-1}$ ) and excellent cycling stability $(98.7 \%$ retention after 10,000 cycles at $10 \mathrm{~A}$ $\mathrm{g}^{-1}$ ) in an aqueous 6-M KOH electrolyte.

\section{Experimental}

\subsection{Preparation of Nitrogen-Doped Porous Carbon}

All chemical reagents are of analytical-grade and used without further purification. To prepare the NPC, isophthalaldehyde ( $1.13 \mathrm{~g}, 8.5 \mathrm{mmol})$, p-phenylenediamine $(0.91 \mathrm{~g}$, $8.5 \mathrm{mmol}$ ), and $2.04 \mathrm{~g}$ of 12-nm silica spheres (mass ratio of $\mathrm{SiO}_{2}$ to the carbon sources is $1: 1$ ) are placed in a zirconium oxide grinding jar with twenty-four 5-mm zirconium oxide grinding balls. The mixture is milled at $500 \mathrm{rpm}$ for $5 \mathrm{~h}$ using an XGB2 planetary ball mill to form a yellow precursor. The precursor is subsequently dried at $80{ }^{\circ} \mathrm{C}$ overnight and pyrolyzed in a tube furnace at $700-1100{ }^{\circ} \mathrm{C}$ for $2 \mathrm{~h}$ at a heating rate of $5{ }^{\circ} \mathrm{C} \mathrm{min}^{-1}$ under an argon atmosphere (denoted as NPC- $T$, where $T$ is the pyrolysis temperature). The silica template is removed by leaching with $2 \mathrm{M} \mathrm{NaOH}$ at $80{ }^{\circ} \mathrm{C}$ for $4 \mathrm{~h}$. The above leaching process is repeated twice to ensure that the silica is completely removed. The final product is washed with water and ethanol until the $\mathrm{pH}$ of the filtrate is approximately 7 and then dried at $80^{\circ} \mathrm{C}$.

NPC-1000-0 and NPC-1000-2 are synthesized following the approach described above, where 1000 indicates that the pyrolysis temperature is $1000{ }^{\circ} \mathrm{C}$, and 0 and 2 indicate the mass of $\mathrm{SiO}_{2}$, which is zero and two times that of the total carbon sources (isophthalaldehyde and p-phenylenediamine).

$\mathrm{Fe}$-doped NPC (Fe-NPC) is also synthesized following the same procedure as NPC-1000, with the addition of $0.081 \mathrm{~g}$ of $\mathrm{FeCl}_{3}$ during ball milling.

\subsection{Material Characterization}

Powder X-ray diffraction (XRD) analysis is conducted using a D8 ADVANCE instrument with $\mathrm{Cu}_{\alpha}$ radiation $(40 \mathrm{kV}$,
$60 \mathrm{~mA}$ ). The morphologies are characterized from scanning electron microscopy (SEM) images obtained using a field emission scanning electron micro-analyzer (FEI Magellan 400), and transmission electron microscopy (TEM; JEM2100F). Raman spectra are obtained with a DXR Raman Microscope (Thermal Scientific Co., USA) with an excitation length of $532 \mathrm{~nm}$. Two spectra are obtained for each sample to ensure accuracy. Nitrogen adsorption-desorption isotherms are measured at $-196{ }^{\circ} \mathrm{C}$ using an ASAP 2010 accelerated surface area and pore size analyzer system (Micrometitics, Norcross, GA). The specific surface areas are obtained following the multipoint Brunauer-Emmett-Teller (BET) method. The pore-size distribution curves, pore volume, and pore diameter are calculated using the adsorption branch of the isotherms following the Barrett-Joyner-Halenda (BJH) method. X-ray photoelectron spectroscopy (XPS) measurements are used to analyze the surface of the samples with an ESCALAB 250 X-ray photoelectron spectrometer and $\mathrm{Al} \mathrm{K}_{\alpha}$ $(h \nu=1486.6 \mathrm{eV})$ radiation.

\subsection{Electrochemical Measurements}

The catalyst ink is prepared by blending the catalyst powder ( $5 \mathrm{mg}$ ) with $20 \mu \mathrm{L}$ of a Nafion solution ( $5 \mathrm{wt} \%$ ), $500 \mu \mathrm{L}$ of ethanol, and $500 \mu \mathrm{L}$ of deionized water in an ultrasonic bath, and $20 \mu \mathrm{L}$ of the catalyst ink is pipetted and spread onto the glassy carbon (GC) electrode (catalyst loading amount of $0.5 \mathrm{mg} \mathrm{cm}^{-2}$ ). For comparison, commercial $20 \mathrm{wt} \%$ platinum on Vulcan carbon black $(\mathrm{Pt} / \mathrm{C})$ with the same loading amount is analyzed under the same conditions.

All electrochemical measurements are conducted in a conventional three-electrode cell using a CHI760E electrochemical workstation ( $\mathrm{CH}$ Instrument) at room temperature. A GC electrode (5.0 $\mathrm{mm}$ diameter) is used as the working electrode, and a saturated calomel electrode (SCE) and graphite rod are used as the reference and counter electrodes, respectively. The ORR electrochemical experiments are conducted in an $\mathrm{O}_{2}$-saturated $0.1 \mathrm{M} \mathrm{KOH}$ electrolyte. To remove the capacitive current of the working electrode, the background current is measured by running the above electrodes in $\mathrm{N}_{2}$-saturated $0.1 \mathrm{M} \mathrm{KOH}$. In the reported ORR polarization curves, the background current is subtracted from the capacitive current. All measured potentials are converted to the potentials versus the reversible hydrogen electrode (RHE) based on $E_{\mathrm{RHE}}=E_{\mathrm{SCE}}+0.2415+0.059 \times \mathrm{pH}$. 
The rotating ring-disk electrode (RRDE) tests are conducted on a GC disk $\left(0.2475 \mathrm{~cm}^{2}\right)$ surrounded by a Pt disk $\left(0.1866 \mathrm{~cm}^{2}\right)$. The ring potential is maintained at $1.21 \mathrm{~V}$ (vs. RHE) to detect the production of $\mathrm{H}_{2} \mathrm{O}_{2}$ species. The number of electrons transferred $(n)$ and percentage of $\mathrm{H}_{2} \mathrm{O}_{2}$ released $\left(\% \mathrm{H}_{2} \mathrm{O}_{2}\right)$ during the ORR process are calculated using Eqs. 1 and 2, respectively:

$n=4 \frac{I_{\mathrm{d}}}{I_{\mathrm{d}}+I_{\mathrm{r}} / N}$

$\% \mathrm{H}_{2} \mathrm{O}_{2}=200 \frac{I_{\mathrm{r}} / N}{I_{\mathrm{d}}+I_{\mathrm{r}} / N}$

where $I_{\mathrm{d}}$ is the disk current, $I_{\mathrm{r}}$ is the ring current, and $N$ (the value is 0.37) is the collection efficiency of the Pt ring electrode.

\subsection{Zn-Air Battery Measurements}

Liquid $\mathrm{Zn}$-air battery $(\mathrm{ZAB})$ tests are conducted using a homemade $\mathrm{Zn}$-air cell. The air cathode consists of a hydrophobic carbon paper with a gas diffusion layer on the airfacing side and a catalyst layer on the water-facing side. The loading amount for all catalysts is $0.25 \mathrm{mg} \mathrm{cm}^{-2}$. A polished $\mathrm{Zn}$ plate with a thickness of $0.3 \mathrm{~mm}$ is used as the anode. The electrolyte used for $\mathrm{ZAB}$ is $6.0 \mathrm{M} \mathrm{KOH}$ containing $0.20 \mathrm{M} \mathrm{Zn}(\mathrm{Ac})_{2}$. To evaluate the potential of NPC-1000 in a real device, NPC-1000 and NiFe-LDH (NiFe-layered double hydroxide) with a mass ratio of 1:1 are used as the air cathode. $\mathrm{NiFe}-\mathrm{LDH}$ achieves excellent OER activity, which reduces the charging voltage of the $\mathrm{Zn}$-air battery. Cycling tests are conducted using a Land CT2001A system, and each discharge and charge period are set to be $30 \mathrm{~min}$. The charge-discharge polarization curve is tested using a PINE electrochemical workstation (Pine Research Instrumentation, USA). For comparison, a mixture of noble metal $\mathrm{Pt} / \mathrm{C}$ and $\mathrm{RuO}_{2}$ (mass ratio 1:1) with the same loading amount is also tested.

\subsection{Supercapacitor Measurements}

Supercapacitor measurements are also conducted in a conventional three-electrode cell using a CHI760E electrochemical workstation ( $\mathrm{CH}$ Instrument) at room temperature. The ink and electrode are prepared following the same method as those for ORR testing. The electrolyte used for the supercapacitor measurement is 6-M KOH. The gravimetric-specific capacitance $\left(C_{\mathrm{m}}\right.$ in $\left.\mathrm{F} \mathrm{g}^{-1}\right)$ based on the galvanostatic charge/ discharge profile and $\mathrm{CV}$ curve is calculated using Eq. 3:

$C_{\mathrm{m}}=\frac{i \times \Delta t}{m \times \Delta V}$

where $i(A)$ is the discharge current, $\Delta V(V)$ is the potential window within the discharge time $\Delta t(\mathrm{~s})$, and $m(\mathrm{~g})$ is the mass loading of the electrode material.

$C_{m}=\frac{1}{m \nu\left|V_{\mathrm{a}}-V_{\mathrm{b}}\right|} \int_{V_{\mathrm{b}}}^{V_{\mathrm{a}}} i(V) \mathrm{d} V$

where $m$ is the mass loading of the electrode material, $\nu$ is the scan rate, $V_{\mathrm{a}}$ and $V_{\mathrm{b}}$ are the cathodic and anodic potentials, respectively, and $i(V)$ is the current response at potential $V$.

\section{Results and Discussion}

Figure 1 shows the nitrogen-doped porous carbon preparation process. First, the condensation reaction of isophthalaldehyde and p-phenylenediamine produces a yellow polymer precursor, and the $\mathrm{SiO}_{2}$ nanospheres are uniformly dispersed during ball milling. Second, high-temperature pyrolysis combined with the removal of the $\mathrm{SiO}_{2}$ template leads to the formation of the sheetlike NPCs with large numbers of micropores and mesopores (Fig. 2a, b). The porous structure is further verified by the TEM images (Fig. 2c). The high-resolution TEM images show lattice fringes with lattice spacing of $0.34 \mathrm{~nm}$ consistent with the (002) facet of graphitic carbon. The distribution of nitrogen can be confirmed by the elemental mapping (Fig. 2e, f) and indicates that nitrogen atoms are successfully doped into the carbon skeleton, which is essential for good ORR activity and wettability [32].

The XRD patterns are studied to investigate the microstructures and textural properties of NPCs. Figure 3a shows the XRD patterns of the NPCs carbonized at different temperatures. The two broad diffraction peaks at approximately $2 \theta=23^{\circ}$ and $44^{\circ}$ are indexed to the (002) and (101) diffraction of graphitic carbon, respectively. The high intensity in the low-angle region of the XRD patterns is attributed to the high number of pores in the NPC samples [33]. Raman spectroscopy is a nondestructive, fast, high-resolution testing method that provides the most structural and electronic information regarding carbon materials [34]. As shown in Fig. 3b, the two peaks 


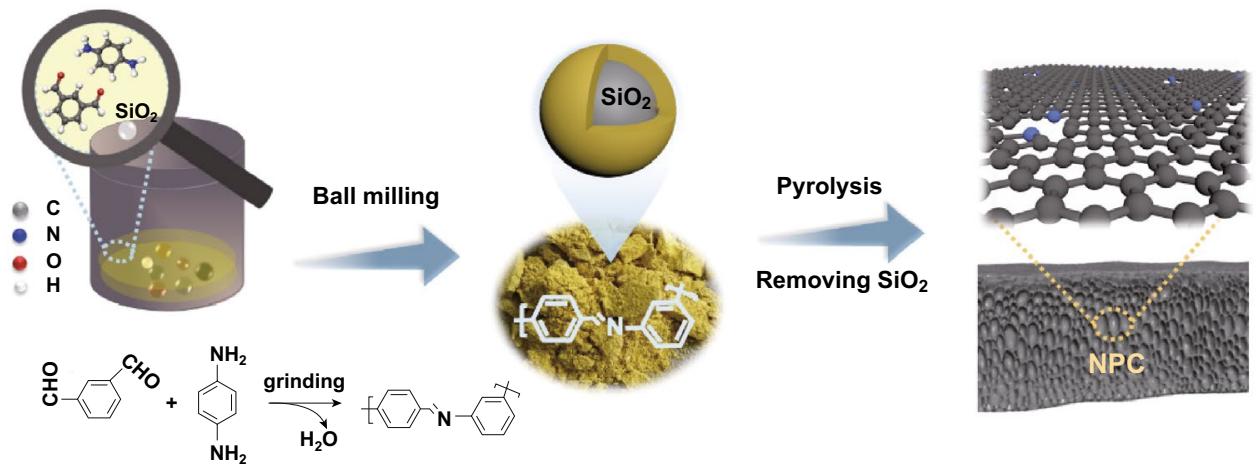

Fig. 1 Schematic representation of the preparation of N-doped porous carbon (NPC) via a mechanochemical route
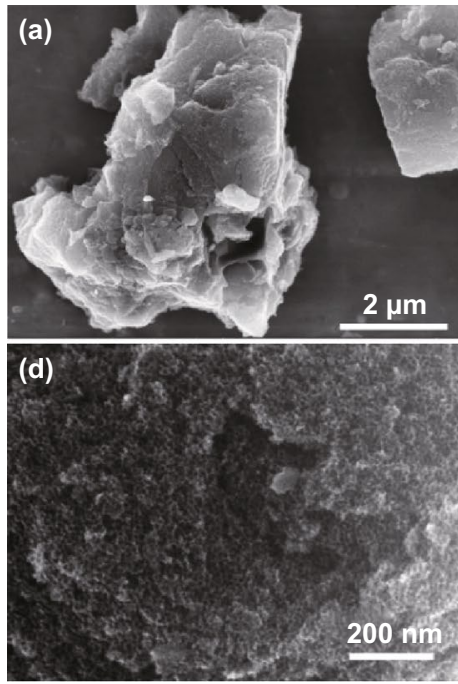
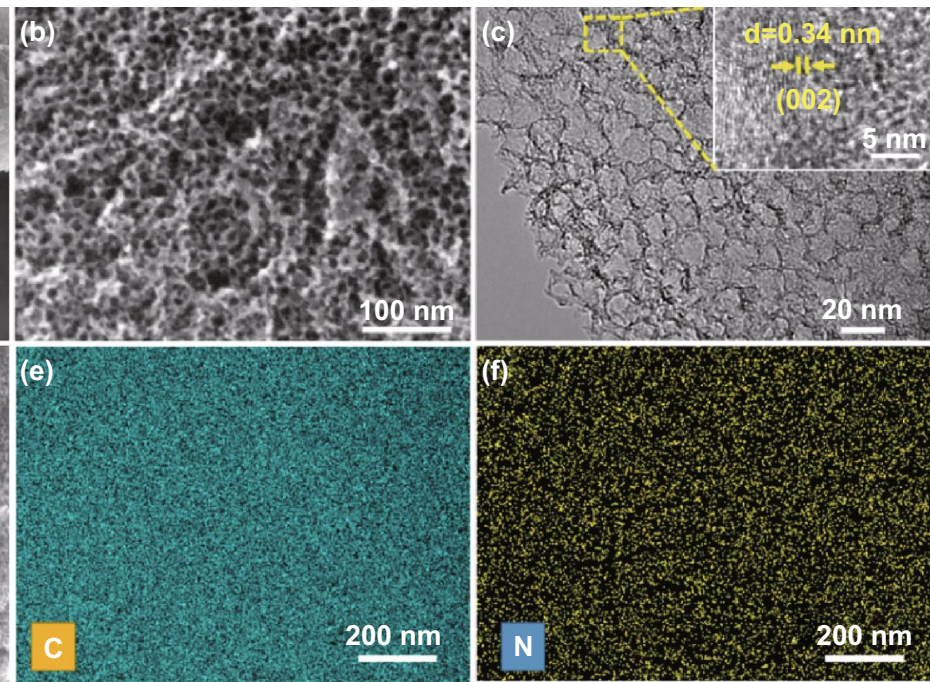

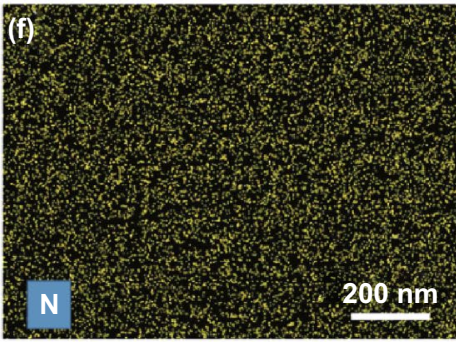

Fig. 2 a, b SEM, and c TEM images of NPC-1000, d-f SEM image of NPC-1000 and corresponding elemental mapping images of C and N

at approximately 1340 and $1590 \mathrm{~cm}^{-1}$, corresponding to the D and $\mathrm{G}$ peaks, are characteristic of the defective graphitic and graphitic layers, respectively. The significant $\mathrm{G}$ peak indicates the presence of a graphitized carbon structure, consistent with TEM and XRD results. The ratio of the intensity of the $\mathrm{D} / \mathrm{G}$ bands $\left(I_{\mathrm{D}} / I_{\mathrm{G}}\right)$ can be used to characterize the defects in the carbon material. The $I_{\mathrm{D}} / I_{\mathrm{G}}$ value gradually increases as the carbonization temperature increases, indicating a higher number of defects at higher temperatures. The porosity of the as-prepared material is obtained from the $\mathrm{N}_{2}$ adsorption-desorption isotherm curves. Figure $3 \mathrm{c}$ shows the combined type-I/ IV isotherms that indicate the presence of micropores
$(<2 \mathrm{~nm})$ and mesopores $(2-50 \mathrm{~nm})$. The micropores are mainly derived from the carbonization of the polymer, and the mesopores are produced by the removal of silica nanospheres. As indicated by the pore-size distribution curves in the inset of Fig. 3c, uniform mesopores are present, centering at approximately $15 \mathrm{~nm}$. To explore the effect of temperature and silica template content on the porous structure, the $\mathrm{N}_{2}$ adsorption-desorption isotherms and pore-size distribution curves of NPC-800, NPC-1100, NPC-1000-0 (without $\mathrm{SiO}_{2}$ ), and NPC-1000-2 (mass ratio of $\mathrm{SiO}_{2}$ to carbon source is 2) are also obtained (Fig. S1), and the results are presented in Table $\mathrm{S} 1$. The results show that the Brunauer-Emmett-Teller surface area $\left(S_{\mathrm{BET}}\right)$ and 

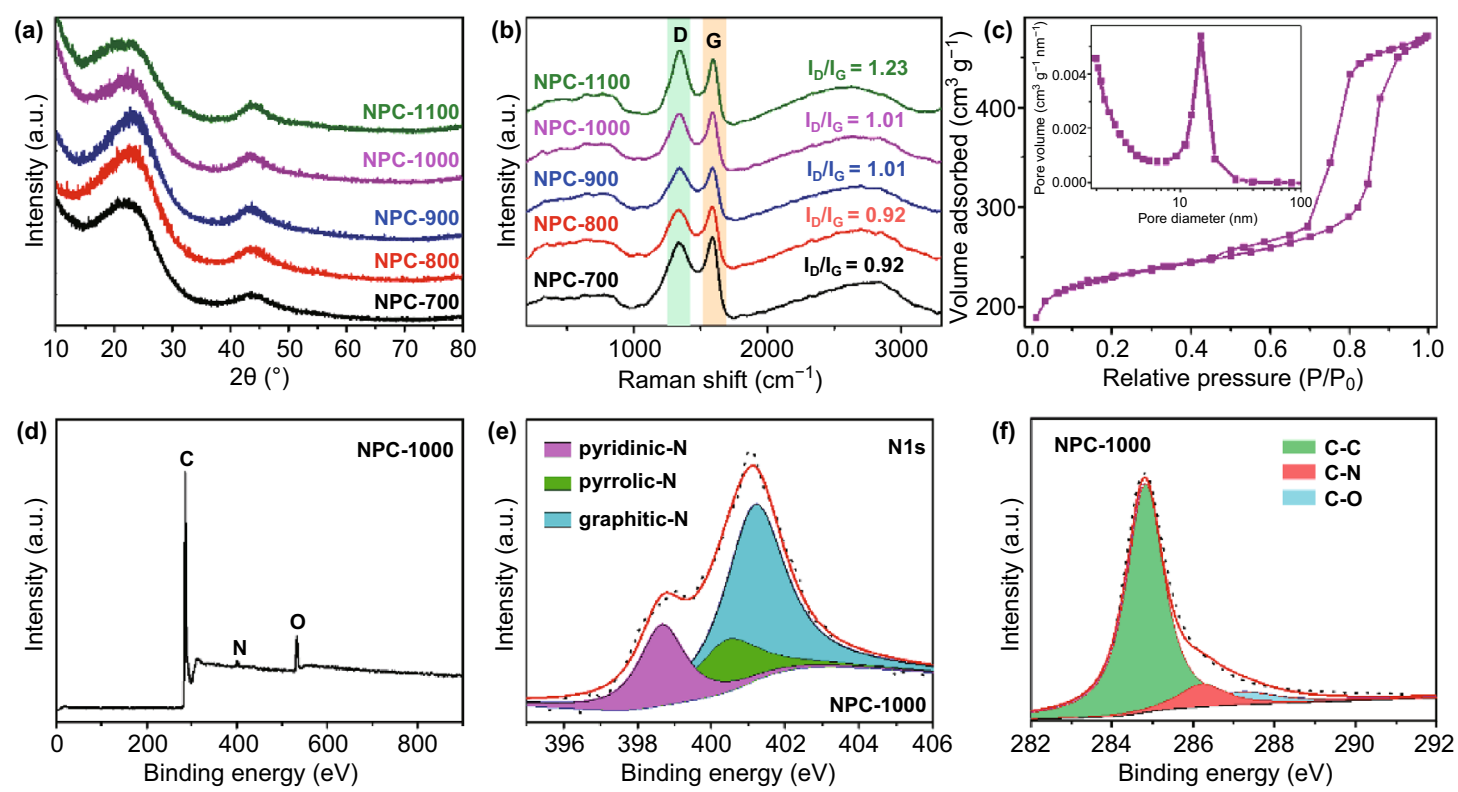

Fig. 3 a XRD patterns and b Raman spectra of different NPCs, $\mathbf{c}$ nitrogen adsorption-desorption isotherms of NPC-1000 (inset: pore-size distribution), $\mathbf{d}$ XPS spectra, and $\mathbf{e}, \mathbf{f}$ high-resolution N 1s and C1s spectra of NPC-1000

micropore area gradually improve with increasing temperature. That is, high-temperature carbonization will lead to the formation of more micropores. The generation of numerous micropores and mesopores will create more edge sites and defects, which is consistent with the change of $I_{\mathrm{D}} / I_{\mathrm{G}}$ values in the Raman spectra. The hierarchical micro-mesopore structure facilitates electron and ion transport during the reaction $[21,35,36]$. The micropore area $\left(118 \mathrm{~m}^{2} \mathrm{~g}^{-1}\right)$ and specific surface area $\left(140 \mathrm{~m}^{2} \mathrm{~g}^{-1}\right)$ of NPC-1000-0 are almost the same, confirming that the mesopores in NPC-1000 are derived from the removal of the $\mathrm{SiO}_{2}$ template and the micropores are derived from the pyrolysis of polymers. The use of a higher $\mathrm{SiO}_{2}$ content for NPC-1000-2 results in a smaller specific surface area due to the collapse of the pore structure.

The surface chemical compositions and surroundings of the as-prepared samples are investigated by XPS analysis, and an XPS survey scan of the NPC-1000 is presented in Fig. 3d, which shows the three peaks attributable to $\mathrm{C}, \mathrm{N}$, and $\mathrm{O}$. This suggests that $\mathrm{N}$ atoms are still present in the carbon subjected to high-temperature pyrolysis. The highresolution $\mathrm{N} 1 s$ spectra show three peaks for pyridinic $\mathrm{N}$ $(\sim 398.7 \mathrm{eV})$, pyrrolic $\mathrm{N}(\sim 400.5 \mathrm{eV})$, and graphitic $\mathrm{N}$ $(\sim 401.2 \mathrm{eV})$ [21, 37]. Previous studies demonstrated that pyridinic $\mathrm{N}$ and graphitic $\mathrm{N}$ are beneficial for improving the electrochemical performance, as N-doping could modify the electronic structure and improve the surface hydrophilicity, conductivity, and adsorption performance, as well as the Fermi levels of the adjacent carbon atoms [38-41]. The presence of $\mathrm{C}-\mathrm{N}$ in the high-resolution $\mathrm{C} 1 s$ spectra further confirms that $\mathrm{N}$ atoms are doped into the carbon skeleton. For comparison, the XPS of NPC-800 and NPC-1100 are also measured (Fig. S2, Table S2), and the results show that the proportions of pyridinic $\mathrm{N}$, pyrrolic $\mathrm{N}$, and graphitic $\mathrm{N}$ are almost the same after pyrolysis at different temperatures. NPC-800, NPC-1000, and NPC-1100 have nitrogen contents of 4.3, 2.2, and 1.1 at.\%, respectively. That is, the higher the pyrolysis temperature, the lower the nitrogen content. Additionally, the oxygen-containing functional groups on the carbon surface can also affect the doping of $\mathrm{N}$ and promote the introduction of $\mathrm{N}$ to the highly active sites of the carbon lattice [42].

The ORR activity of all NPCs is first evaluated in $0.1 \mathrm{M}$ $\mathrm{KOH}$ at room temperature following the rotating disk electrode (RDE) method. For comparison, commercial Pt/C is also tested. As shown in Fig. 4a, there is a significant reduction peak in the $\mathrm{CV}$ curves of all samples collected in the $\mathrm{O}_{2}$-saturated $0.1 \mathrm{M} \mathrm{KOH}$ solution. The ORR peak potential of NPC-1000 is the most positive, suggesting that its activity is optimum. The linear sweep voltammogram 
(LSV) curves further validate the superior electro-activity of NPC-1000 with higher onset $\left(E_{\text {onset }}=0.9 \mathrm{~V}\right)$ and halfwave $\left(E_{1 / 2}=0.82 \mathrm{~V}\right)$ potentials; these values are only $30 \mathrm{mV}$ lower than those of commercial $\mathrm{Pt} / \mathrm{C}$. The higher limiting current density of NPC-1000 than that of the other catalysts indicates a faster diffusion rate. The excellent ORR activity of NPC-1000 is also indicated by the smaller Tafel slope of $58 \mathrm{mV} \mathrm{dec}{ }^{-1}$. Figure $4 \mathrm{~d}$ compares the onset and half-wave potentials of the catalysts synthesized at different temperatures and indicates that the ORR activity first increases and then decreases with an increase in the pyrolysis temperature. The RDE tests of NPC-1000 are conducted at various rotating rates, and the results fitted by the Koutecky-Levich (K-L) plot are the inverse of the current density $\left(j^{-1}\right)$ as a function of the inverse of the square root of the rotating speed $\left(\omega^{-1 / 2}\right)$ at different potentials (Fig. 4e). The calculated electron transfer number is approximately 3.7, based on the K-L equation, suggesting that the NPC1000-catalyzed ORR process is a primary four-electron reaction, rather than a two-electron reaction. Rotating ring-disk electrode (RRDE) tests are also conducted to calculate the electron transfer number $(n)$ and detect the generation of the two-electron product, $\mathrm{H}_{2} \mathrm{O}_{2}$ (Fig. 4f). The lower peroxide yield and $n$ of approximately 4 further confirm that NPC-1000 performs better in the ORR. A long-term test is necessary to evaluate the durability of the catalysts. The chronoamperometric responses of NPC-1000 and Pt/C catalysts are measured at $0.4 \mathrm{~V}$ (vs. RHE) and $1600 \mathrm{rpm}$ and show that NPC-1000 is more durable than $\mathrm{Pt} / \mathrm{C}$ over a long period (Fig. S3a). Moreover, NPC-1000 is more tolerant to methanol (Fig. S3b).

The effect of specific surface area and pore structure on the catalytic activity of ORR is also investigated by changing the amount of $\mathrm{SiO}_{2}$ template particles. As shown in Fig. S4, NPC-1000 performs better than NPC-1000-0; therefore, a high specific surface area and the presence of mesopores in the hierarchical pore structure are essential for improving ORR. The higher current density of NPC-1000 than that of NPC-1000-2 indicates that the pore structure impacts the diffusion process. The collapse of the NPC-1000-2 mesoporous structure hinders diffusion, resulting in a lower limiting current density than that of NPC-1000.

Our results are consistent with results that demonstrated that nitrogen doping (especially pyridinic and graphitic
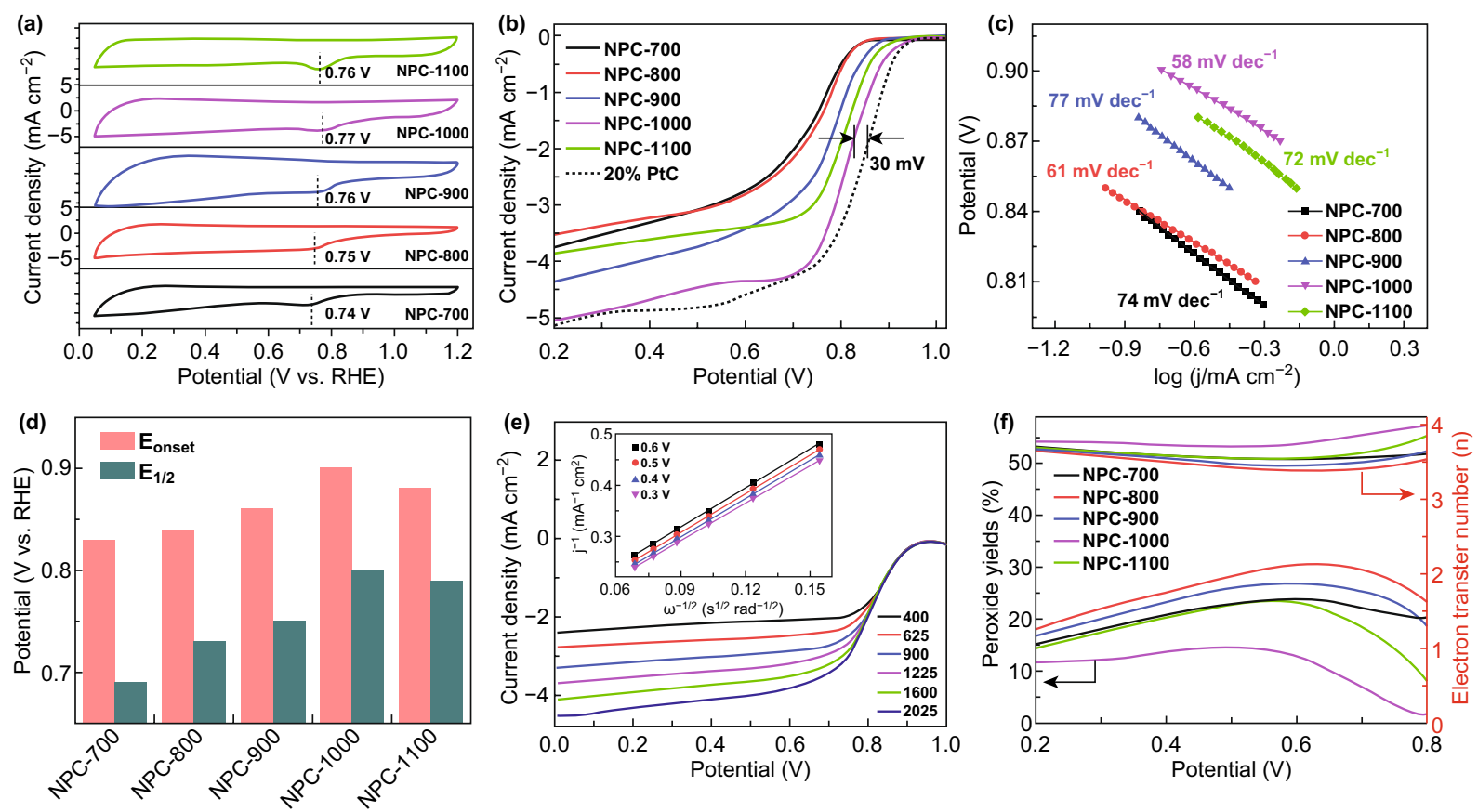

Fig. 4 a Cyclic voltammograms (CVs), b ORR polarization curves (sweep rate: $10 \mathrm{mV} \mathrm{s}^{-1}$; rotation speed: $1600 \mathrm{rpm}$ ) of the as-prepared catalysts in an $\mathrm{O}_{2}$-saturated 0.1-M KOH electrolyte, $\mathbf{c}$ Tafel plots derived from $\mathbf{b}, \mathbf{d}$ comparison of the onset $\left(E_{\text {onset }}\right)$ and half-wave $\left(E_{1 / 2}\right)$ potentials of different catalysts, e LSV curves of NPC-1000 at different rotation speeds (insert shows the corresponding Koutecky-Levich plots), $\mathbf{f}$ peroxide yield and electron transfer number of the as-prepared catalysts at various potentials based on the RRDE data 
nitrogen) plays an important role in ORR electrocatalysis [38-40]. Furthermore, for NPCs, a large specific surface area is beneficial for more active sites and offering good electrical conductivity, which can accelerate electron transport during the reaction process. Considering the above, we speculate that the excellent ORR activity of NPC-1000 is mainly attributed to the high density of active sites, good conductivity, and hierarchical pore structure. First, although the nitrogen contents of NPC-700, NPC-800, and NPC-900 are higher than that of NPC-1000, their low specific surface areas resulted in the incomplete exposure of active sites. Second, although NPC-1100 has a higher specific surface area and conductivity, its nitrogen content is insufficient, resulting in an insufficient number of active sites. Finally, the hierarchically micro-mesoporous structure accelerates the transport of electrons and ions. Therefore, NPC-1000 offers the best ORR activity among all NPCs.

This mechanochemical method is also suitable for preparing porous carbons with metal doping. For example, when $\mathrm{Fe}$ ions are incorporated during ball milling followed by pyrolysis, the resulting Fe-NPC catalyst exhibits outstanding ORR activity that is comparable to that of commercial Pt/C
(Fig. S5). This high ORR activity may be due to the formation of $\mathrm{Fe}-\mathrm{N}_{x}$ sites, which is highly efficient for ORR in an alkaline solution [43-45].

To further investigate the performance of NPC in a real device, we conducted a test on ZABs using NPC-1000 and $\mathrm{NiFe}-\mathrm{LDH}$ as the air cathode and $\mathrm{Zn}$ foil as the anode. $\mathrm{KOH}(6.0 \mathrm{M})$-containing $\mathrm{Zn}(\mathrm{Ac})_{2}(0.20 \mathrm{M})$ is used as an electrolyte (Fig. 5a). For comparison, a mixture of $\mathrm{Pt} / \mathrm{C}$ and $\mathrm{RuO}_{2}$ (mass ratio 1:1) with the same loading amount is also tested under the same conditions. As shown in Fig. 5b, the open-circuit potential of the ZAB with NPC-1000 is approximately $1.43 \mathrm{~V}$. The discharge curves and corresponding power density of the ZAB catalyzed by NPC1000 are comparable to those of $\mathrm{Pt} / \mathrm{C}$ (Fig. 5c), suggesting the superior activity of NPC-1000. Galvanostatic discharge and charge measurements are taken to evaluate the cycling stability (Fig. 5d). The discharge voltage of $\mathrm{Pt} / \mathrm{C}$ and $\mathrm{RuO}_{2}$ decreases greatly after $20 \mathrm{~h}$, while that of the NPC-1000equipped battery remained stable. This result is clearer in Fig. 5e, where the discharge voltage of NPC-1000 is lower than that of the $\mathrm{Pt} / \mathrm{C}$ and $\mathrm{RuO}_{2}$ electrode in the first cycle, and almost the same in the 41 st cycle. However, after 44 (a)

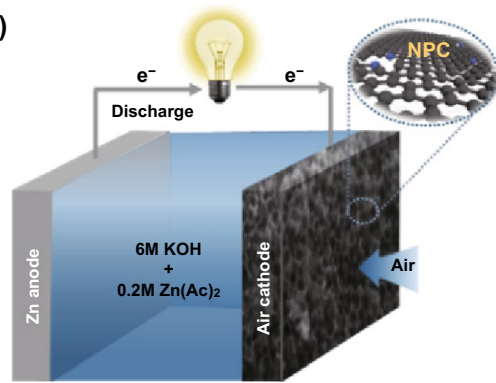

(d)

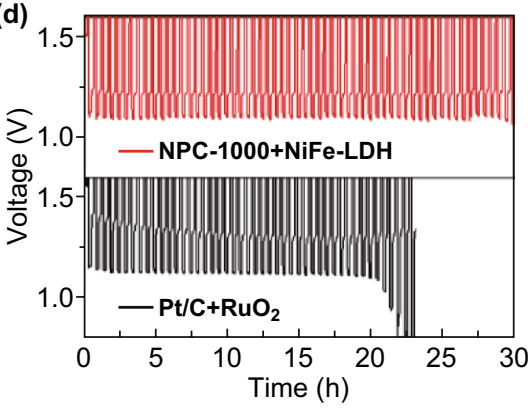

(b)

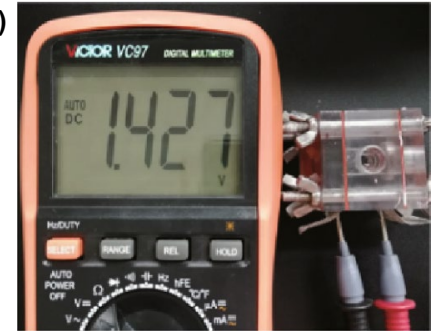

(e)

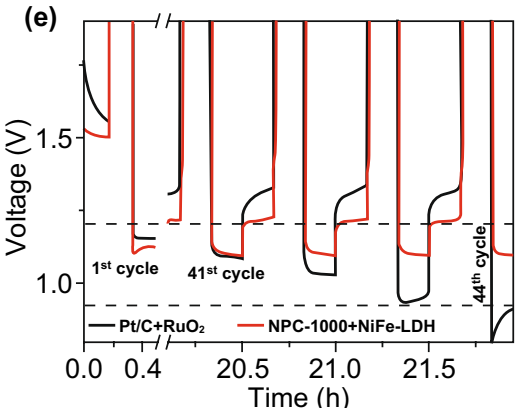

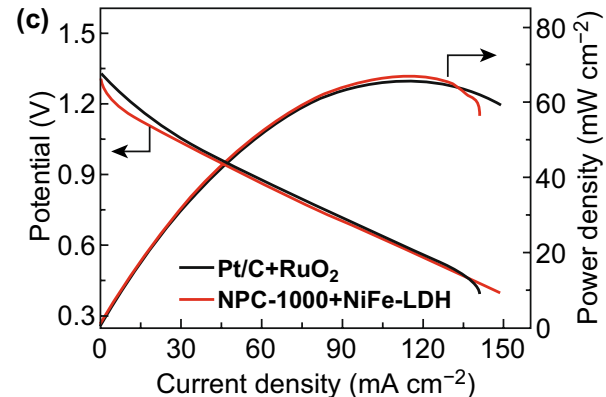

(f)

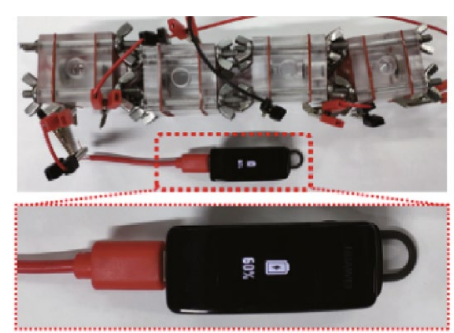

Fig. 5 a Schematic illustration of the Zn-air battery with NPC-1000 as the air cathode, $\mathbf{b}$ image of the ZAB with a measured open-circuit voltage of $1.43 \mathrm{~V}$, c discharge polarization curves and corresponding power-density plots, $\mathbf{d}$, e charge/discharge cycling at $10 \mathrm{~mA} \mathrm{~cm}{ }^{-2}(0.5 \mathrm{~h}$ for each cycle) for a rechargeable ZAB with NPC-1000 and NiFe-LDH as the air cathode, $\mathbf{f}$ image of a Bluetooth headset powered by four ZABs in series 
cycles, the discharge voltage of the $\mathrm{Pt} / \mathrm{C}$ and $\mathrm{RuO}_{2}$-equipped battery decreases rapidly, but the voltage drop of NPC-1000 is negligible. A Bluetooth headset could be charged using four ZABs in series with NPC-1000 (Fig. 5f), demonstrating its promising application in rechargeable ZABs.

As well as ORR electrocatalysis, the as-prepared NPC with high specific surface area, hierarchical micromesoporous structure, and nitrogen doping could also be used in supercapacitors. To demonstrate the supercapacitor performances, we conducted cyclic voltammetry (CV), galvanostatic charge-discharge (GCD), electrochemical impedance spectroscopy (EIS), and long-term cycling stability analysis in a three-electrode configuration. First, the CV curves of NPC-800, NPC-1000, and NPC-1100 exhibit a rectangular-like shape without any pronounced redox peaks (Fig. 6a), indicating the highly electric double-layer capacitive (EDLC) nature and small internal, interfacial, and contact resistances [46]. Unlike that of NPC-700, the CV curves of NPC-800, NPC-1000, and NPC-1100 are all almost rectangular, even at a scan rate of $200 \mathrm{mV} \mathrm{s}^{-1}$ (Fig. S6), and the GCD curves are all quasi-triangular (Figs. 6a and S7), indicating a higher discharge rate [46, 47].

The specific capacitance of the NPC-800 electrode calculated according to the corresponding $\mathrm{CV}$ curves is
$431 \mathrm{~F} \mathrm{~g}^{-1}$ at $10 \mathrm{mV} \mathrm{s}^{-1}$, which is higher than that of the other electrodes. This suggests better capacitive performance when NPC-800 is used in supercapacitors. This capacitance is also higher than those for carbon-based materials reported in the literature [48-50]. All GCD curves exhibit a similar, almost symmetrical, triangular shape, indicating outstanding capacitor-like features, reversibility, and rapid charge transfer. Under the same conditions, the longer charging-discharging duration indicates a higher specific capacity. That is, NPC- 800 has a higher specific capacity $\left(256 \mathrm{~F} \mathrm{~g}^{-1}\right.$ at $\left.0.5 \mathrm{~A} \mathrm{~g}^{-1}\right)$. The capacities of NPC-700, NPC-800, NPC-1000, and NPC1100 are $61 \%, 78 \%, 81 \%$, and $76 \%$, respectively, following a 20 -fold increase in the current density from 0.5 to $10 \mathrm{~A} \mathrm{~g}^{-1}$ (Fig. 6c). The higher capacity retention rates of NPC-800 and NPC-1000 under different current densities indicate their excellent rate performances. Excluding NPC700, all Nyquist plots are measured by EIS (Fig. 6d) and present almost vertical lines in the low-frequency region, indicating nearly ideal capacitive behavior, and rapid ion diffusion and transport [51]. Additionally, no distinct semicircles are observed in the high-frequency region, demonstrating a low charge-transfer resistance [52]. After 10,000 cycles of constant current charge-discharge at a current
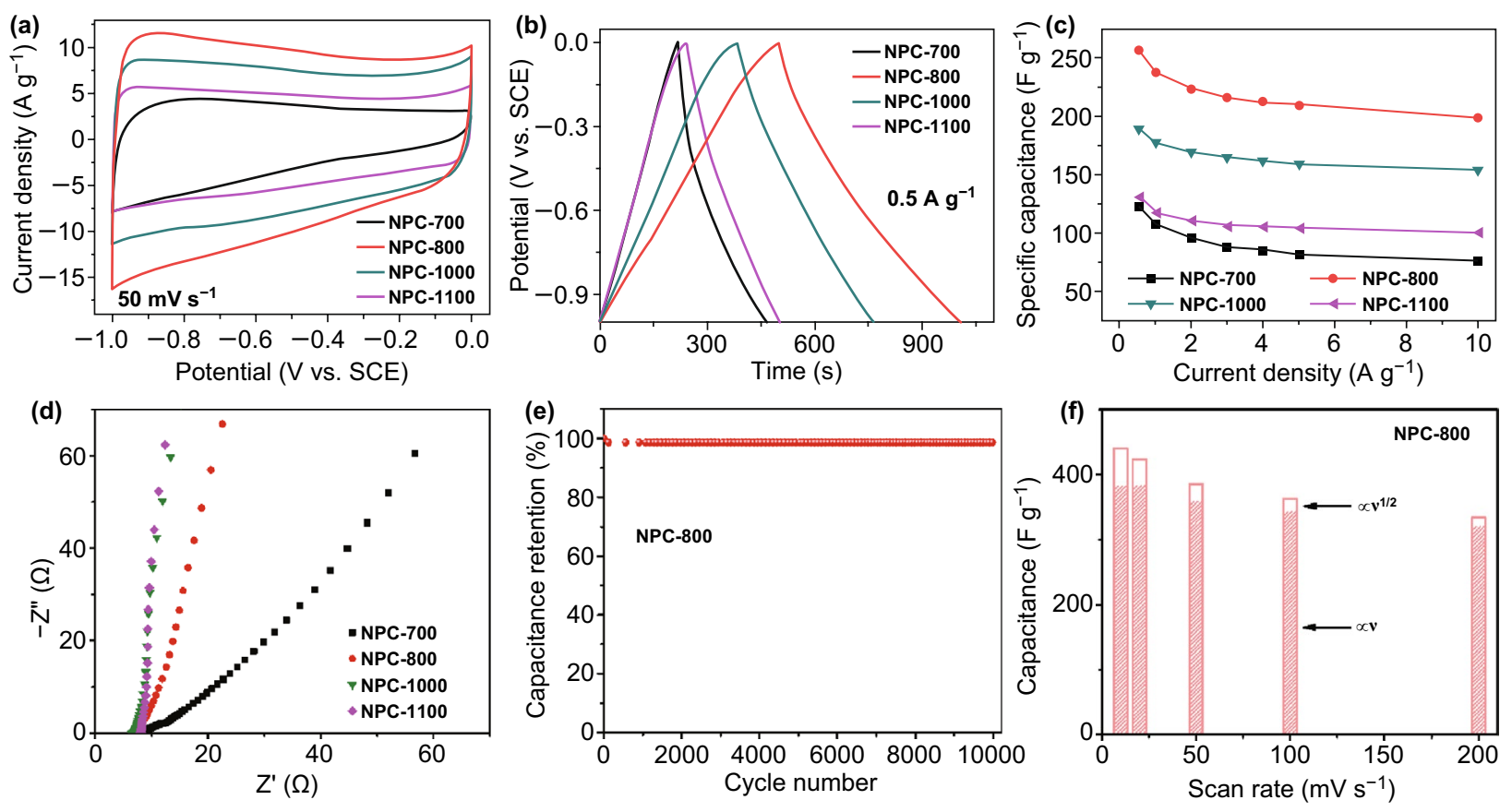

Fig. 6 a CV curves at $50 \mathrm{mV} \mathrm{s}^{-1}$, b GCD curves at $0.5 \mathrm{~A} \mathrm{~g}^{-1}$, $\mathbf{c}$ variations in the specific capacitances at different current densities and d Nyquist plots of NPC-700, NPC-800, NPC-1000, and NPC-1100 in a 6-M KOH electrolyte, e cycling performance of NPC-800 at a current density of $10 \mathrm{~A} \mathrm{~g}^{-1}$, f deconvolution of the charge contribution as a function of the scan rate 
density of $10 \mathrm{~A} \mathrm{~g} \mathrm{~g}^{-1}, 98.7 \%$ of the initial specific capacity of NPC-800 is maintained (Fig. 6e). This confirms the excellent cycling stability of this material. To better understand the charge storage procedures, the dependence of the current $(i)$ on the scan rate $(\nu)$ is analyzed. The current at a specific potential $(i(V))$ is a combination of capacitive $\left(k_{1} \nu\right)$ and diffusion-limited $\left(k_{2} \nu^{1 / 2}\right)$ processes, according to Eq. $5[53,54]$ :

$i(V)=k_{1} v+k_{2} v^{1 / 2}$

where $k_{1}$ and $k_{2}$ are fitting parameters that are proportionality constants related to the capacitive and diffusion-limited processes, respectively. Figure $6 \mathrm{f}$ shows the $C_{\mathrm{m}}$ and fraction of current attributed to two different charge-storage processes. The capacitive effects are significantly higher than the diffusion-controlled contributions from the electrode, indicating that the large $C_{\mathrm{m}}$ of NPC-800 electrode mainly originates from the capacitive response. The capacitive response of the NPC-800 electrode is almost constant over a wide range of scan rates $\left(10-200 \mathrm{mV} \mathrm{s}^{-1}\right)$, further demonstrating the excellent rate performance of NPC-800. As shown in Figs. S8 and $\mathrm{S} 9$, when the pyrolysis temperature is insufficient (less than $800^{\circ} \mathrm{C}$ ), the diffusion-controlled capacitance ratio is relatively high. That is, the NPCs obtained at a low temperature with a lower specific surface area and conductivity hinder the transport of ions and electrons. As the temperature increases $\left(\geq 800^{\circ} \mathrm{C}\right)$, the specific surface area increases and the conductivity is enhanced. Hence, diffusion is no longer the factor limiting the capacitance. NPC-800 has a smaller specific surface area and lower electrical conductivity than NPC-1000 and NPC-1100, but a higher $C_{m}$, and could contribute to better surface wettability due to the higher $\mathrm{N}$ content (Table S2) [23, 55-57].

\section{Conclusions}

In summary, we prepared $\mathrm{N}$-containing polymer precursors via mechanochemical polymerization without a solvent or catalyst, followed by pyrolysis and the removal of the $\mathrm{SiO}_{2}$ template to obtain hierarchical micro-mesoporous NPCs. Owing to the sufficient hierarchical pore structure, high specific surface area, and nitrogen doping, the NPC-1000 prepared by this method exhibited excellent ORR electrocatalytic activity, stability, and methanol tolerance. When used as a ZAB cathode, NPC-1000 exhibited excellent discharge performance comparable to that of $\mathrm{Pt} / \mathrm{C}$. Furthermore, its discharge stability is much better than that of $\mathrm{Pt} / \mathrm{C}$. The NPC-800 prepared by the same method also exhibited excellent supercapacitance performance due to its high specific capacity $\left(256 \mathrm{~F} \mathrm{~g}^{-1}\right.$ at $0.5 \mathrm{~A} \mathrm{~g}^{-1}$ and $431 \mathrm{~F} \mathrm{~g}^{-1}$ at $\left.10 \mathrm{mV} \mathrm{s}^{-1}\right)$. A high rate performance and excellent cycling stability $\left(98.7 \%\right.$ retention after 10,000 cycles at $\left.10 \mathrm{~A} \mathrm{~g}^{-1}\right)$ in an aqueous 6-M KOH solution were observed. This study confirmed the feasibility of preparing nitrogen-containing polymers by ball milling to prepare NPCs with high electrocatalytic activity, which could replace noble-metal electrocatalytic materials.

Acknowledgements The authors are grateful to the financial support from NSFC (51602332), the National Key Research and Development Program of China (2016YFB0700204), Science and Technology Commission of Shanghai Municipality (15520720400, 16DZ2260603), and Equipment Research Program (6140721050215). M. Yang would like to thank the National 1000 Youth Talents program of China and financial support from Ningbo 3315 program. T.T. thanks DST Solar Energy Harnessing Centre (DST/TMD/SERI/HUB/1(C)), DST Materials for Energy Storage program, Ministry of Electronics and Information Technology (India) (Project ID: ELE1819353MEITNAK).

Open Access This article is licensed under a Creative Commons Attribution 4.0 International License, which permits use, sharing, adaptation, distribution and reproduction in any medium or format, as long as you give appropriate credit to the original author(s) and the source, provide a link to the Creative Commons licence, and indicate if changes were made. The images or other third party material in this article are included in the article's Creative Commons licence, unless indicated otherwise in a credit line to the material. If material is not included in the article's Creative Commons licence and your intended use is not permitted by statutory regulation or exceeds the permitted use, you will need to obtain permission directly from the copyright holder. To view a copy of this licence, visit http://creativecommons.org/licenses/by/4.0/.

Electronic supplementary material The online version of this article (https://doi.org/10.1007/s40820-019-0364-z) contains supplementary material, which is available to authorized users.

\section{References}

1. M. Zhou, Y. Xu, Y. Lei, Heterogeneous nanostructure array for electrochemical energy conversion and storage. Nano Today 20, 33-57 (2018). https://doi.org/10.1016/j.nanto d.2018.04.002

2. S.K. Singh, K. Takeyasu, J. Nakamura, Active sites and mechanism of oxygen reduction reaction electrocatalysis on nitrogen-doped carbon materials. Adv. Mater. 31, 1804297 (2019). https://doi.org/10.1002/adma.201804297

3. M.L. Pegis, C.F. Wise, D.J. Martin, J.M. Mayer, Oxygen reduction by homogeneous molecular catalysts and 
electrocatalysts. Chem. Rev. 118, 2340-2391 (2018). https:// doi.org/10.1021/acs.chemrev.7b00542

4. X. Liu, L. Dai, Carbon-based metal-free catalysts. Nat. Rev. Mater. 1, 16064 (2016). https://doi.org/10.1038/natrevmats .2016 .64

5. M.H. Naveen, K. Shim, M.S.A. Hossain, J.H. Kim, Y.-B. Shim, Template free preparation of heteroatoms doped carbon spheres with trace $\mathrm{Fe}$ for efficient oxygen reduction reaction and supercapacitor. Adv. Energy Mater. 7, 1602002 (2017). https://doi.org/10.1002/aenm.201602002

6. T. Zhou, Y. Zhou, R. Ma, Z. Zhou, G. Liu, Q. Liu, Y. Zhu, J. Wang, In situ formation of nitrogen-doped carbon nanoparticles on hollow carbon spheres as efficient oxygen reduction electrocatalysts. Nanoscale 8, 18134-18142 (2016). https:// doi.org/10.1039/c6nr06716f

7. K.P. Gong, F. Du, Z.H. Xia, M. Durstock, L.M. Dai, Nitrogendoped carbon nanotube arrays with high electrocatalytic activity for oxygen reduction. Science 323, 760-764 (2009). https ://doi.org/10.1126/science.1168049

8. L. Yang, S. Jiang, Y. Zhao, L. Zhu, S. Chen et al., Borondoped carbon nanotubes as metal-free electrocatalysts for the oxygen reduction reaction. Angew. Chem. Int. Ed. 50, 71327135 (2011). https://doi.org/10.1002/anie.201101287

9. T. Zhou, R. Ma, Y. Zhou, R. Xing, Q. Liu, Y. Zhu, J. Wang, Efficient N-doping of hollow core-mesoporous shelled carbon spheres via hydrothermal treatment in ammonia solution for the electrocatalytic oxygen reduction reaction. Microporous Mesoporous Mater. 261, 88-97 (2018). https://doi. org/10.1016/j.micromeso.2017.10.050

10. Z. Yang, Z. Yao, G.F. Li, G.Y. Fang, H.G. Nie et al., Sulfurdoped graphene as an efficient metal-free cathode catalyst for oxygen reduction. ACS Nano 6, 205-211 (2012). https://doi. org/10.1021/nn203393d

11. G. Fu, Z. Cui, Y. Chen, L. Xu, Y. Tang, J.B. Goodenough, Hierarchically mesoporous nickel-iron nitride as a cost-efficient and highly durable electrocatalyst for $\mathrm{Zn}$-air battery. Nano Energy 39, 77-85 (2017). https://doi.org/10.1016/j. nanoen.2017.06.029

12. B. Ashourirad, M. Demir, R.A. Smith, R.B. Gupta, H.M. El-Kaderi, Rapid transformation of heterocyclic building blocks into nanoporous carbons for high-performance supercapacitors. RSC Adv. 8, 12300-12309 (2018). https://doi. org/10.1039/c8ra00546j

13. C. Vix-Guterl, E. Frackowiak, K. Jurewicz, M. Friebe, J. Parmentier, F. Béguin, Electrochemical energy storage in ordered porous carbon materials. Carbon 43, 1293-1302 (2005). https ://doi.org/10.1016/j.carbon.2004.12.028

14. D. Gu, Y. Zhou, R. Ma, F. Wang, Q. Liu, J. Wang, Facile synthesis of $\mathrm{N}$-doped graphene-like carbon nanoflakes as efficient and stable electrocatalysts for the oxygen reduction reaction. Nano-Micro Lett. 10, 29 (2018). https://doi.org/10.1007/s4082 0-017-0181-1

15. Y. Deng, Y. Xie, K. Zou, X. Ji, Review on recent advances in nitrogen-doped carbons: preparations and applications in supercapacitors. J. Mater. Chem. A 4, 1144-1173 (2016). https ://doi.org/10.1039/c5ta08620e

16. R. Yang, M. Li, S.Q. Liu, D.P. Qiu, W.J. Xu, Preparation of cork-derived porous activated carbon for high performance supercapacitors. J. Inorg. Mater. 34, 625 (2019). https://doi. org/10.15541/jim20180426

17. M. Demir, S.K. Saraswat, R.B. Gupta, Hierarchical nitrogendoped porous carbon derived from lecithin for high-performance supercapacitors. RSC Adv. 7, 42430-42442 (2017). https://doi.org/10.1039/c7ra07984b

18. E. Frackowiaka, F. Beguin, Carbon materials for the electrochemical storage of energy in capacitors. Carbon 39, 937-995 (2001). https://doi.org/10.1016/S0008-6223(00)00183-4

19. B. Fang, J.H. Kim, M.-S. Kim, A. Bonakdarpour, A. Lam, D.P. Wilkinson, J.-S. Yu, Fabrication of hollow core carbon spheres with hierarchical nanoarchitecture for ultrahigh electrical charge storage. J. Mater. Chem. 22, 19031-19038 (2012). https://doi.org/10.1039/c2jm33435f

20. E. Proietti, F. Jaouen, M. Lefevre, N. Larouche, J. Tian, J. Herranz, J.P. Dodelet, Iron-based cathode catalyst with enhanced power density in polymer electrolyte membrane fuel cells. Nat. Commun. 2, 416 (2011). https://doi.org/10.1038/ncomms 1427

21. R. Xing, T. Zhou, Y. Zhou, R. Ma, Q. Liu, J. Luo, J. Wang, Creation of triple hierarchical micro-meso-macroporous $\mathrm{N}$-doped carbon shells with hollow cores toward the electrocatalytic oxygen reduction reaction. Nano-Micro Lett. 10, 3 (2018). https://doi.org/10.1007/s40820-017-0157-1

22. A. Ignaszak, S. Ye, E. Gyenge, A study of the catalytic interface for $\mathrm{O}_{2}$ electroreduction on Pt: The interaction between carbon support meso/microstructure and ionomer (Nafion) distribution. J. Phys. Chem. C 113, 298-307 (2008). https:// doi.org/10.1021/jp8060398

23. Y. Li, I. Hussain, J. Qi, C. Liu, J. Li et al., N-doped hierarchical porous carbon derived from hypercrosslinked diblock copolymer for capacitive deionization. Sep. Purif. Technol. 165, 190-198 (2016). https://doi.org/10.1016/j.seppur.2016.04.007

24. M. Demir, B. Ashourirad, J.H. Mugumya, S.K. Saraswat, H.M. El-Kaderi, R.B. Gupta, Nitrogen and oxygen dual-doped porous carbons prepared from pea protein as electrode materials for high performance supercapacitors. Int. J. Hydrogen Energy 43, 18549-18558 (2018). https://doi.org/10.1016/j. ijhydene.2018.03.220

25. M. Zhong, E.K. Kim, J.P. McGann, S.E. Chun, J.F. Whitacre, M. Jaroniec, K. Matyjaszewski, T. Kowalewski, Electrochemically active nitrogen-enriched nanocarbons with well-defined morphology synthesized by pyrolysis of self-assembled block copolymer. J. Am. Chem. Soc. 134, 14846-14857 (2012). https://doi.org/10.1021/ja304352n

26. S. Wang, J. Zhang, P. Shang, Y. Li, Z. Chen, Q. Xu, N-doped carbon spheres with hierarchical micropore-nanosheet networks for high performance supercapacitors. Chem. Commun. 50, 12091-12094 (2014). https://doi.org/10.1039/c4cc04832f

27. Y. Zhao, M. Liu, X. Deng, L. Miao, P.K. Tripathi et al., Nitrogen-functionalized microporous carbon nanoparticles 
for high performance supercapacitor electrode. Electrochim. Acta 153, 448-455 (2015). https://doi.org/10.1016/j.elect acta.2014.11.173

28. E. Zhang, G.P. Hao, M.E. Casco, V. Bon, S. Grätz, L. Borchardt, Nanocasting in ball mills-combining ultra-hydrophilicity and ordered mesoporosity in carbon materials. J. Mater. Chem. A 6, 859-865 (2018). https://doi.org/10.1039/c7ta1 0783h

29. P. Basnet, E. Anderson, Y. Zhao, Hybrid $\mathrm{Cu}_{\mathrm{x}} \mathrm{O}-\mathrm{TiO}_{2}$ nanopowders prepared by ball milling for solar energy conversion and visible-light-induced wastewater treatment. ACS Appl. Nano Mater. 2, 2446-2455 (2019). https://doi.org/10.1021/ acsanm.9b00325

30. L. Liao, Q. Zhang, Z. Su, Z. Zhao, Y. Wang et al., Efficient solar water-splitting using a nanocrystalline $\mathrm{CoO}$ photocatalyst. Nat. Nanotechnol. 9, 69-73 (2014). https://doi. org/10.1038/nnano.2013.272

31. J. Wang, Q. Liu, An efficient one-step condensation and activation strategy to synthesize porous carbons with optimal micropore sizes for highly selective $\mathrm{CO}_{2}$ adsorption. Nanoscale 6, 4148-4156 (2014). https://doi.org/10.1039/c3nr0 $5825 \mathrm{e}$

32. X. Liu, H. Liu, M. Mi, W. Kong, Y. Ge, J. Hu, Nitrogen-doped hierarchical porous carbon aerogel for high-performance capacitive deionization. Sep. Purif. Technol. 224, 44-50 (2019). https://doi.org/10.1016/j.seppur.2019.05.010

33. Y. Zhu, S. Murali, M.D. Stoller, K.J. Ganesh, W. Cai et al., Carbon-based supercapacitors produced by activation of graphene. Science 332, 1537-1541 (2011). https://doi. org/10.1126/science. 1200770

34. A.C. Ferrari, Raman spectroscopy of graphene and graphite: disorder, electron-phonon coupling, doping and nonadiabatic effects. Solid State Commun. 143, 47-57 (2007). https://doi. org/10.1016/j.ssc.2007.03.052

35. Z. Tang, Z. Pei, Z. Wang, H. Li, J. Zeng et al., Highly anisotropic, multichannel wood carbon with optimized heteroatom doping for supercapacitor and oxygen reduction reaction. Carbon 130, 532-543 (2018). https://doi.org/10.1016/j.carbo n.2018.01.055

36. J.C. Wang, M.J. Yang, Y.F. Zhu, R.G. Ma, W.T. He, Renewable porous carbons prepared by $\mathrm{KOH}$ activation as oxygen reduction electrocatalysts. J. Inorg. Mater. (2019). https://doi. org/10.15541/jim20190036

37. B. Bayatsarmadi, Y. Zheng, M. Jaroniec, S.Z. Qiao, Soft-templating synthesis of $\mathrm{N}$-doped mesoporous carbon nanospheres for enhanced oxygen reduction reaction. Chem. Asian J. 10, 1546-1553 (2015). https://doi.org/10.1002/asia.201500287

38. P.H. Matter, U.S. Ozkan, Non-metal catalysts for dioxygen reduction in an acidic electrolyte. Catal. Lett. 109, 115-123 (2006). https://doi.org/10.1007/s10562-006-0067-1

39. T. Iwazaki, R. Obinata, W. Sugimoto, Y. Takasu, High oxygen-reduction activity of silk-derived activated carbon. Electrochem. Commun. 11, 376-378 (2009). https://doi. org/10.1016/j.elecom.2008.11.045

40. X. Bao, X. Nie, D. Deak, E.J. Biddinger, W. Luo, V. Asthagiri, U.S. Ozkan, C.M. Hadad, A first-principles study of the role of quaternary- $\mathrm{N}$ doping on the oxygen reduction reaction activity and selectivity of graphene edge sites. Top. Catal. 56, 1623-1633 (2013). https://doi.org/10.1007/s1124 4-013-0097-z

41. M. Terrones, P.M. Ajayan, F. Banhart, X. Blase, D.L. Carroll et al., N-doping and coalescence of carbon nanotubes: synthesis and electronic properties. Appl. Phys. A Mater. Sci. Process. 74, 355-361 (2002). https://doi.org/10.1007/s0033 90201278

42. X. Li, H. Wang, J.T. Robinson, H. Sanchez, G. Diankov, H. Dai, Simultaneous nitrogen doping and reduction of graphene oxide. J. Am. Chem. Soc. 131, 15939-15944 (2009). https:// doi.org/10.1021/ja907098f

43. T. Zhou, R. Ma, T. Zhang, Z. Li, M. Yang, Q. Liu, Y. Zhu, J. Wang, Increased activity of nitrogen-doped graphene-like carbon sheets modified by iron doping for oxygen reduction. J. Colloid Interface Sci. 536, 42-52 (2019). https://doi. org/10.1016/j.jcis.2018.10.021

44. H. Shen, T. Thomas, S.A. Rasaki, A. Saad, C. Hu, J. Wang, $\mathrm{M}$. Yang, Oxygen reduction reactions of $\mathrm{Fe}-\mathrm{NC}$ catalysts: current status and the way forward. Electrochem. Energy Rev. 2, 252-276 (2019). https://doi.org/10.1007/s41918-019-00030-w

45. P. Xu, H.H. Song, Z.K. Ma, D.L. Wang, Y.E. Xie, Fe-N modified carbon black as a high-performance and cost-effective cathode catalyst in microbial fuel cells. J. Inorg. Mater. 33, 295-300 (2018). https://doi.org/10.15541/jim20170136

46. L.T. Ma, C.Y. Zhi, Fe, N doped 2D porous carbon bifunctional catalyst for zinc-air battery. J. Inorg. Mater. 34, 103-108 (2019). https://doi.org/10.15541/jim20180260

47. B.-J. Yoon, S.-H. Jeong, K.-H. Lee, S.H. Kim, C.G. Park, J.H. Han, Electrical properties of electrical double layer capacitors with integrated carbon nanotube electrodes. Chem. Phys. Lett. 388, 170-174 (2004). https://doi.org/10.1016/j.cplet t.2004.02.071

48. Y. Wang, Z. Shi, Y. Huang, Y. Ma, C. Wang, M. Chen, Y. Chen, Supercapacitor devices based on graphene materials. J. Phys. Chem. C 113, 13103-13107 (2009). https://doi. org/10.1021/jp902214f

49. G. Zhu, T. Chen, Y. Hu, L. Ma, R. Chen et al., Recycling PM 2.5 carbon nanoparticles generated by diesel vehicles for supercapacitors and oxygen reduction reaction. Nano Energy 33, 229-237 (2017). https://doi.org/10.1016/j.nanoen.2017.01.038

50. J. Wang, J. Tang, B. Ding, V. Malgras, Z. Chang et al., Hierarchical porous carbons with layer-by-layer motif architectures from confined soft-template self-assembly in layered materials. Nat. Commun. 8, 15717 (2017). https://doi.org/10.1038/ ncomms 15717

51. H. Zhou, Y. Zhou, L. Li, Y. Li, X. Liu, P. Zhao, B. Gao, Amino acid protic ionic liquids: multifunctional carbon precursor for N/S codoped hierarchically porous carbon materials toward supercapacitive energy storage. ACS Sustain. Chem. Eng. 7, 9281-9290 (2019). https://doi.org/10.1021/acssuschem eng.9b00279

52. S. Song, F. Ma, G. Wu, D. Ma, W. Geng, J. Wan, Facile selftemplating large scale preparation of biomass-derived 3D hierarchical porous carbon for advanced supercapacitors. J. Mater. 
Chem. A 3, 18154-18162 (2015). https://doi.org/10.1039/ c5ta04721h

53. V. Strauss, K. Marsh, M.D. Kowal, M. El-Kady, R.B. Kaner, A simple route to porous graphene from carbon nanodots for supercapacitor applications. Adv. Mater. 30, 1704449 (2018). https://doi.org/10.1002/adma.201704449

54. T. Ling, P. Da, X. Zheng, B. Ge, Z. Hu et al., Atomic-level structure engineering of metal oxides for high-rate oxygen intercalation pseudocapacitance. Sci. Adv. 4, 6261 (2018). https://doi.org/10.1126/sciadv.aau6261

55. J. Shao, X. Zhou, Q. Liu, R. Zou, W. Li, J. Yang, J. Hu, Mechanism analysis of the capacitance contributions and ultralong cycling-stability of the isomorphous $\mathrm{MnO}_{2} @ \mathrm{MnO}_{2}$ core/ shell nanostructures for supercapacitors. J. Mater. Chem. A 3, 6168-6176 (2015). https://doi.org/10.1039/c4ta06793b

56. G. Lota, K. Lota, E. Frackowiak, Nanotubes based composites rich in nitrogen for supercapacitor application. Electrochem. Commun. 9, 1828-1832 (2007). https://doi.org/10.1016/j. elecom.2007.04.015

57. G. Wang, J. Zhang, S. Kuang, J. Zhou, W. Xing, S. Zhuo, Nitrogen-doped hierarchical porous carbon as an efficient electrode material for supercapacitors. Electrochim. Acta 153, 273-279 (2015). https://doi.org/10.1016/j.elect acta.2014.12.006 